Program Progress Report

CDRL A002

\title{
Pilot-in-the-loop Method Development
}

2012 Basic and Applied Research in Sea-Based Aviation

ONR \#BAA12-SN-0028

REPORT No. 9/C576

PERIOD 20 May 2014 to 20 June 2014

Prepared by

Combustion Research and Flow Technology, Inc. (CRAFT Tech)

6210 Keller's Church Rd.

Pipersville, PA 18947

Phone: 215/766-1520; Fax: 215/766-1524

Attn: J. Shipman

Email: shipman@craft-tech.com

\section{June 2014}

Prepared for

Naval Air Warfare Center AD

48110 Shaw Road, Code 4.3.2.1

Patuxent River, MD 20670

Arlington, VA 22203-1995

Attn: $\quad$ Dr. Susan Polsky, Code 4.3.2.1

Phone: 301.342.8575

Email: susan.polsky@navy.mil

Prepared under

Contract Number: N00014-13-C-0456

PERIOD: 20 September 2013 to 20 September 2016

DISTRIBUTION STATEMENT A: Distribution Approved for public release; distribution is unlimited. 


\section{Report Documentation Page}

Form Approved

OMB No. 0704-0188

Public reporting burden for the collection of information is estimated to average 1 hour per response, including the time for reviewing instructions, searching existing data sources, gathering and maintaining the data needed, and completing and reviewing the collection of information. Send comments regarding this burden estimate or any other aspect of this collection of information,

including suggestions for reducing this burden, to Washington Headquarters Services, Directorate for Information Operations and Reports, 1215 Jefferson Davis Highway, Suite 1204, Arlington

VA 22202-4302. Respondents should be aware that notwithstanding any other provision of law, no person shall be subject to a penalty for failing to comply with a collection of information if it

does not display a currently valid OMB control number.

1. REPORT DATE

SEP 2014
2. REPORT TYPE
3. DATES COVERED

20-05-2014 to 20-06-2014

4. TITLE AND SUBTITLE

Pilot-in-the-loop Method Development

6. $\operatorname{AUTHOR}(\mathrm{S})$

5a. CONTRACT NUMBER

5b. GRANT NUMBER

5c. PROGRAM ELEMENT NUMBER

5d. PROJECT NUMBER

5e. TASK NUMBER

5f. WORK UNIT NUMBER

7. PERFORMING ORGANIZATION NAME(S) AND ADDRESS(ES)

Combustion Research and Flow Technology, Inc. (CRAFT Tech),6210

8. PERFORMING ORGANIZATION REPORT NUMBER

Keller's Church Rd.,Pipersville,PA,18947

9. SPONSORING/MONITORING AGENCY NAME(S) AND ADDRESS(ES)

10. SPONSOR/MONITOR'S ACRONYM(S)

11. SPONSOR/MONITOR'S REPORT

NUMBER(S)

12. DISTRIBUTION/AVAILABILITY STATEMENT

Approved for public release; distribution unlimited

13. SUPPLEMENTARY NOTES

14. ABSTRACT

15. SUBJECT TERMS

16. SECURITY CLASSIFICATION OF:

a. REPORT

unclassified b. ABSTRACT

unclassified c. THIS PAGE

unclassified
17. LIMITATION OF ABSTRACT

Same as

Report (SAR)
18. NUMBER 19a. NAME OF

OF PAGES RESPONSIBLE PERSON

6

Standard Form 298 (Rev. 8-98) Prescribed by ANSI Std Z39-18 


\section{Pilot-in-the-loop Method Development 2012 Basic and Applied Research in Sea-Based Aviation ONR \#BAA12-SN-0028}

PERIOD 20 May 2014 to 20 June 2014

\section{PROJECT OVERVIEW}

The goal of this project is to integrate novel numerical modeling and computer hardware approaches to compute the non-linear aerodynamic coupling between the ship and aircraft in such a way that execution times are at real-time speeds, allowing for pilot-in-the-loop CFD to be integrated in the piloted flight simulation environment. To achieve the speed gains required, three areas will be targeted for implementation into the CFD simulation framework: (1) numerical algorithms, (2) novel domain boundaries, and (3) Graphical Processing Unit (GPU) hardware. A framework will be established to link the CFD with realtime simulations. A building block approach will be employed to first demonstrate non-realtime integration of the CFD simulation framework with helicopter flight dynamic models, then realtime execution for a minimum fidelity airwake/aircraft simulation, then build to higher fidelity realtime simulations.

\subsection{Project Technical Objectives}

The project involves the following seven tasks to accomplish the technical objectives of the project:

Task 1: Implement modular implicit/explicit solver

Task 2: Apply structured numerics

Task 3: Apply subdomain with immersed boundary

Task 4: Implement higher order explicit solver for GPU execution

Task 5: Integrate with the GENHEL-PSU flight dynamics model

Task 6: Demonstrate flight simulation in the PSU Rotorcraft Simulation Facility

Task 7: Demonstrate flight Simulation in NAVAIR Manned Flight Simulator 


\section{WORK SUMMARY}

During this reporting period, solver development was performed in two areas: (1) the incompressible formulation employed by the CRUNCH CFD code for CFD airwake simulations was implemented in the structured CRAFT CFD solver (which previously only included a fully compressible formulation) to improve the structured airwake solutions, and (2) an approach has been developed for integrating both the CRAFT CFD and CRUNCH CFD solvers within a common simulation framework (this will make possible combining solver speedups from tasks 1 to 4 in the future).

\subsection{Incorporation of Preconditioned Incompressible Formulation for Structured Solver}

Wake calculations needed for conducting landing simulations on naval ships requires flowfield simulations at low Mach numbers. CRUNCH CFD has modeled such simulations using an incompressible variant of the preconditioning formulation to the NavierStokes equations. Specifically, this has enabled larger time-stepping and improved numerical stability, particularly in regions of sharp geometric discontinuities. The incompressible formulation was incorporated into the structured CRAFT CFD flow solver based on these improved numerical stability observations. This will also permit better flowfield handshaking consistency between CRAFT CFD and CRUNCH CFD for dual solver operations, explained in the next section. Unit problem checkout studies (simple block structured LHA airwake grid, Figure 1) using CRAFT CFD have indicated time-steps consistent with those taken by CRUNCH CFD. Additionally, a 20\% runtime acceleration per iteration over the standard preconditioning formulation has been achieved.

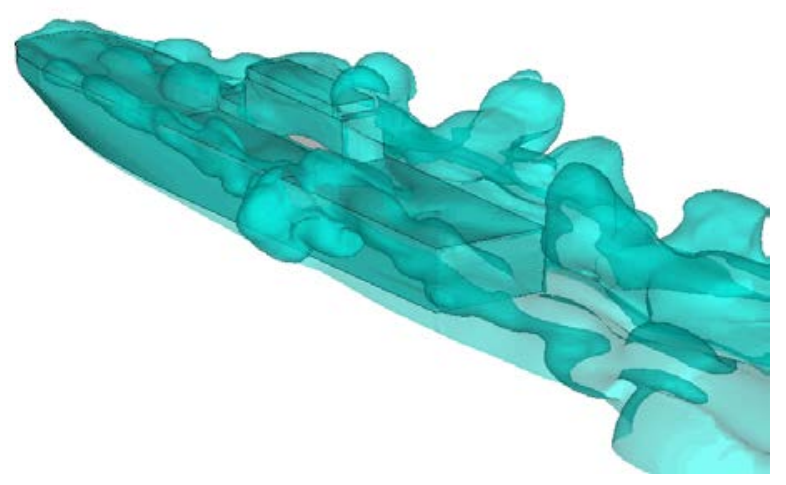

Figure 1: Snapshot of example LHA airwake solution computed by CRAFT CFD with the preconditioned incompressible formulation. 


\subsection{MPMD Approach for integrating Structured and Unstructured Solver Capabilities}

Fast-running and accurate ship wake flowfield computations are challenged by the need for very large computational domain meshes and need to resolve deck boundary layer, bluff body regions, and impact of superstructure geometry on flowfield unsteadiness in regions of aircraft landing. While unstructured tetrahedral meshes are ideal for efficiently meshing complex geometries, such as ship masts and antennae, large mesh densities are needed to ensure good cell quality and minimize grid dissipation due to grid skewness. Conversely, hexahedral cells are best suited for resolving deck surface regions and boundary layers. Hexahedral regions are often constructed using structured mesh generators. Computational overhead and implicit per-iteration runtime costs are generally significantly less for structured solvers.

Given the challenge of providing ship wake unsteadiness in real-time to support pilot-in-the-loop simulations for carrier landing simulations, there is a need to combine the computational efficiency of structured meshes with the geometric flexibility of unstructured meshes. To assist in meeting this objective a Multiple-Process / Multiple-Domain (MPMD) approach has been adopted to combine modeling capabilities of CRAFT CFD and CRUNCH CFD within a common simulation framework. Specifically, a generalized library has been developed to permit data transfers at specified boundaries between independently running executables of these two flow solvers. Inter-communicators within the MPI library are established during initialization to determine which processors from each solver must exchange data with the corresponding solvers on the adjacent domain assigned to another solver. Once specialized inter-solver boundary conditions are written within each solver for handling the data transferred from another solver, a generalized MPI runtime library establishes a message passing link between the two solvers. This eliminates the need for one solver to become essentially a dependent subroutine within another solver and so maintains code modeling flexibility and upgradability. This allows the ship wake runtime requirements and calculations to benefit by combining the modeling experiences from each solver without needing to perform extensive, costly, and error-prone source code integration prior to simulation. At present this technique will be demonstrated using CRUNCH CFD and CRAFT CFD, but this approach is sufficiently generalized to permit interfacing with other flow solvers and interdisciplinary models as well. 
An example of how such an approach could be utilized is shown in , where the nearfield structured grid surrounding the ship (CRAFT CFD solver) communicates with an unstructured farfield domain (CRUNCH CFD solver) via the inter-solver boundary condition highlighted with the red dashed line. Such an approach will be important later in the program when solver improvements targeting both the structured and unstructured solvers can be integrated to a single simulation framework.

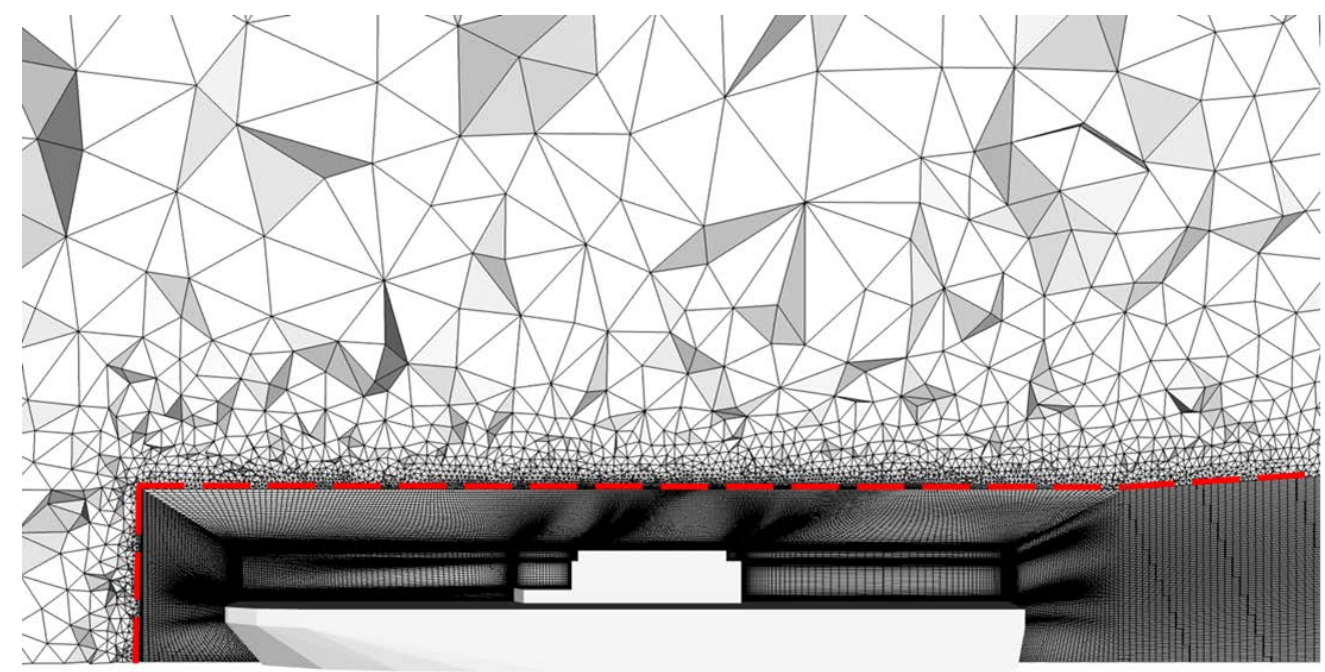

Figure 2: Schematic of MPMD approach.

\section{TECHNICAL/COST STATUS AND PROBLEM AREAS}

No technical or financial problems have been encountered.

\section{MEETING AND/OR TRAVEL}

N/A

\section{CONTRACT SCHEDULE}

The program is proceeding as planned.

\section{PLANNED ACTIVITIES FOR NEXT REPORTING PERIOD}

During the next reporting period a structured multi-block grid for the LHD ship geometry will be obtained and comparison simulations will be initiated to complete a verification of the structured solver improvements and applicability of the structured numeric to airwake simulations. 
Report Distribution per CDRLs for Contract No. N00014-13-C-0456

\begin{tabular}{|c|c|c|c|}
\hline ADDRESSEE & $\begin{array}{l}\text { DODAAC } \\
\text { CODE }\end{array}$ & $\begin{array}{l}\text { UNCLASSIFIED/ } \\
\text { UNLIMITED }\end{array}$ & $\begin{array}{l}\text { UNCLASSIFIED/ } \\
\text { UNLIMITED }\end{array}$ \\
\hline $\begin{array}{l}\text { Program Officer: Mr. John Kinzer } \\
\text { ONR Code } 351 \\
\text { Email: john.kinzer@navy.mil }\end{array}$ & N00014 & 1 & 1 \\
\hline $\begin{array}{l}\text { Program Officer: Ms. Susan Polsky } \\
\text { NAVAIR 4.3.2.1 } \\
\text { Email: susan.polsky@navy.mil }\end{array}$ & N00024 & 1 & 1 \\
\hline $\begin{array}{l}\text { Administrative Contracting Officer* } \\
\text { S3915A }\end{array}$ & S3915A & 1 & 1 \\
\hline $\begin{array}{l}\text { Director, Naval Research Lab } \\
\text { Attn: Code 5596 } \\
4555 \text { Overlook Ave. SW } \\
\text { Washington, D.C. 20375-5320 } \\
\text { Email: reports@library.nrl.navy.mil }\end{array}$ & N00173 & 1 & 1 \\
\hline $\begin{array}{l}\text { Defense Technical Information Center } \\
\text { 8725 John J. Kingman Rd, } \\
\text { STE 0944 } \\
\text { Ft. Belvoir, VA 22060-6218 } \\
\text { Email: } \underline{\text { r@dtic.mil }}\end{array}$ & HJ4701 & 1 & 1 \\
\hline
\end{tabular}

*Send only a copy of the transmittal letter to the Administrative Contracting Officer, do not send actual report to the Administrative Contracting Officer.

ELECTRONIC SUBMISSIONS OF TECHNICAL REPORTS IS PREFERRED AND ENCOURAGED. ELECTONIC SUBMISSION SHOULD BE SENT TO THE EMAIL ADDRESSES PROVIDED IN THE ABOVE TABLE, HOWEVER PLEASE NOTE THE FOLLOWING:

- Only Unlimited/Unclassified document copies may be submitted by email.

- Unclassified/Limited has restricted distribution and a classified document (whether in its entirety or partially) is to be distributed in accordance with classified material handling procedures.

- Electronic submission to DIRECTOR, NAVAL RESEARCH LAB, shall be unclassified./unlimited reports and 30 pages or less. If unclassified and more than 30 pages, hardcopies of reports must be mailed.

- Electronic submission to DTIC shall be unclassified/unlimited reports. 